\title{
SOBRE LA NOCION DE «ACADEMIA» EN EL SIGLO XVIII ESPAÑOL
}

Un lugar común, de difusión persistente, vincula las Academias del siglo XVIII a las iniciativas borbónicas y a la imagen ofrecida en Europa por determinadas sociedades adjetivadas de sabias. En verdad, sabemos hoy que desde finales del siglo XVI y comienzos del XVII se constituyen en España grupos de origen privado, consagrados a la lectura y a la discusión de obras poéticas ${ }^{1}$. Otros grupos documentan otras preocupaciones: en el Madrid de Felipe II, de quién recibió ayuda y protección, funcionó una

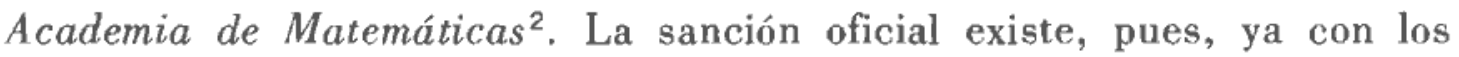
Reyes de la Casa de Austria ${ }^{3}$, y la inserción en las corrientes renacentistas, y por ende la influencia italiana, son datos igualmente a tener en cuenta ${ }^{4}$. El lazo existente entre el nacimiento de aquellas primeras academias modernas y los movimientos de renovación estética o científica, configura, en la parte que le corresponde, la tradición intelectual con que se nutrió el «primer siglo dieciocho» ${ }^{5}$.

1 Vd. J. Sánchez, Academias literarias del Siglo de Oro español, Madrid, 1961. Una perspectiva más general de los antecedentes de las academias españolas del siglo XVIII es la de F. Aguilar Piñal, La Real Academia sevillana de Buenas Letras, en el siglo XVIII, Madrid, 1966, p. 3-7.

2 Vd. J. M. López Piñero, V. Navarro Brotons, E. Portela, Materiales para la historia de las ciencias en España. Siglos XVI-XVII, Valencia, 1976, p. 8.

3 Cf. las Reales Cédulas de 25 de diciembre de 1582 y de 25 de diciembre de 1584 (Ibidem, p. 21-22).

4 Según F. Aguilar Piñal, op. cit., existían en Italia, a principios del siglo XVIII, no menos de seiscientas academias. A. Mestre, Los origenes de la Ilustración, in Historia 16, Extra VIII, 1978, p. 62-64, ha puesto énfasis en la importancia que tuvo en la formación de hombres como Nicolás Antonio, Sáenz de Aguirre y otros «novatores» el contacto con el ambiente intelectual italiano.

5 Cf. A. Mestre, Despotismo e Ilustración en España, Barcelona, 1976 (en particular 
Parece, sin embargo, necesario elucidar el contenido que recubre el término «academia», que no es único. En su día F. López indicó el valor metodológico de una consideración periodizadora del «convoy semántico» con que las Luces se van abriendo paso ${ }^{6}$. Quizás esta orientación metodológica deba ser completada con la consideración de las diversas transformaciones que, en la práctica y en el decurso del tiempo, experimenta un mismo vocablo o concepto. A F. Aguilar Piñal no se le habían escapado, en su libro sobre la Real Academia sevillana de Buenas Letras ${ }^{7}$, las oscilaciones semánticas del término «academia». Recientemente, en estas mismas páginas, A. Gil Novales se refería ${ }^{8}$, al concepto de academia en el siglo XVIII español. Si el lector de las sugestivas páginas de Gil Novales aprendía mucho sobre la idea que ciertos ilustrados se hacían de las academias, y, en particular, de la anhelada Academia Universal de Ciencias y Artes, sacaba menos en limpio sobre el concepto propiamente dicho de las academias, un concepto que conviene deslindar, para saber, en cada caso, de qué se está hablando.

Hay que partir de la identificación originaria entre el Estudio General o la Universidad y el término «academia», tal como aparece registrada en el Diccionario de Autoridades ${ }^{9}$. En el seno de la Universidad-Academia nacieron las academias, entendiendo por tales los torneos, concursos o justas literarias ${ }^{10}$, que de actividades ocasionales pasaron a convertirse en organización permanente. Estas academias universitarias existen, desde luego, en el siglo XVIII ${ }^{11}$, durante el cual diferentes Planes de Estudios tratan de

sobre «el problema de los orígenes de la Ilustración española», p. 11-53), y F. López, Juan Pablo Forner et la crise de la conscience espagnole au XVIII siècle, Bordeaux, 1976, p. 35-208.

6 F. López, La historia de las ideas en el siglo XVIII: concepciones antiguas y revisiones necesarias, in Boletin del Centro de Estudios del siglo XVIII, Oviedo, 3, 1975, p. 3-18.

7 F. Aguilar Piñal, op. cit., p. 4.

8 A Gil Novales, El concepto de Academia de Ciencias en el siglo XVIII español, in Boletín del Centro... cit, 7-8, 1980, p. 3-23.

9 Según el Diccionario, «Academia entre los Latinos (de quienes la tomaron los Españoles) se llama el Estudio general, dicho comúnmente Universidad, donde se enseñan las ciencias y facultades, como Salamanca, Alcalá, Valladolid y otras partes».

10 Así el Diccionario de Autoridades registra otro sentido del término «academias» definidas como «Juntas literarias o Certámenes que ordinariamente se hacen para celebrar alguna acción grande, canonización de Santo, o para ejercitarse los ingenios que las componen, y casi siempre son de Poesía, sobre diferentes asuntosm.

11 M. Peset y J. L. Peset, El reformismo de Carlos III y la Universidad de Salamanca. Plan General de Estudios dirigido a la Universidad de Salamanca por el Real y Supremo Consejo de Castilla en 1771, Acta Salmanticensia, 16, Universidad de Salamanca, 1969, p. 27, n. 2, cita algunos documentos que atestiguan la existencia de dichas academias universitarias: 
reorganizar o de crear academias concebidas como seminarios o «repetitorios» a los que se dota de un contenido práctico («práctica forense», «oratoria», «clínica»...), de acuerdo con algunos planteamientos renovadores ${ }^{12}$. No eran éstos, sin embargo, totalmente inocentes.

En los Planes se trataba de recuperar una pedagogía que se estaba desarrollando fuera de los recintos universitarios. En su Plan de Estudios para la Facultad de Medicina de Salamanca (1766), Francisco Vélez y Juan A. Medina advertían que los estudiantes de Medicina hacían «su principal estudio en las Academias particulares en que se juntan» ${ }^{13}$. Pérez Bayer, en el Memorial por la libertad de la literatura española (1770), opinaba que, en Salamanca, «donde únicamente se aprendía algo y se ejercitaban los que tenían ya principios de Jurisprudencia civil, para poder leer de oposición, era en la Academia que se tenía en el Colegio Trilingüe» ${ }^{14}$. El autor señalaba que esta academia se había instalado, luego, en la Universidad, «en la misma forma que tenía en el Colegio Trilingüe», y que en la Universidad funcionaba también una academia de Cánones, estando presididas ambas academias por sendos manteístas. Precisamente en Salamanca el Plan de $1771^{15}$ consagró la existencia de academias en la Universidad ${ }^{16}$. Fuera de la Universidad funcionaban en Alcalá «dos Academias públicas de Cánones y Leyes, intituladas de Nuestra Señora de Regla y de San José,

Reales Decretos de 7 de diciembre de 1720 y de 6 de febrero de 1721 para Huesca; Reales Cédulas de 1737 y 1740 para Alcalá; Estatutos de la Pontificia y Real Universidad y Estudio General de Zaragoza (1753). Véase, también, en relación con esta última Universidad el Plan que presenta el estado actual de la Universidad literaria de Zaragoza. Dispuesto por D. Inocencio Carrión, Zaragoza, 1769. Por cierto que Zaragoza fue una de las primeras ciudades en que funcionó una Academia de Letrados. La fundó, en 1733, don José Manuel de Gaspar y Segovia, Fiscal de la Real Audiencia de Aragón y, luego, consejero en el de Hacienda, y de ella formó parte el mismo Tomás de Azpuru que fundara, más tarde, en Madrid, la Junta de Jurisprudencia Práctica. Colocada, primero, bajo el patrocinio de la Audiencia, consiguió, en 1770, «incorporarse» (como lo hacían los colegios de abogados de otras ciudades con el de Madrid) a la Academia de Santa Bárbara, y, en 1772, ver aprobados sus estatutos por una Real Cédula que le confería «el título de Real Academia en los términos que le está concedido a la de esta Corte». También funcionaron Academias de letrados en Barcelona, Valladolid, Valencia, Granada... Aquí sólo se tendrá en cuenta a las de Madrid.

12 Vd. M. y J. L. Peset, La Universidad española (siglos XVIII y XIX). Despotismo ilustrado y revolución liberal, Madrid, 1974, p. 160-161, y 290-291.

13 Vd. F. Aguilar Piñal, Los comienzos de la crisis universitaria en España (antología de textos), Madrid, 1967, p. 229.

14 Ibidem, p. 230.

15 Real Provisión de 3 de agosto de 1771 y Real Cédula de 22 de enero de 1786. Estos dos textos constituyeron un modelo, pues fueron recogidos en la Novísima Recopilación (ley IX, tít. VII, lib. VIII, n. 3), bajo la rúbrica «Modo y fin de asistir a las Academias de las Universida- 
fundadas con aprobación del Consejo» ${ }^{17}$. Esta aprobación databa de los años 1737 y 1740, durante los cuales «se despacharon dos Reales Cédulas a favor de las Academias, por las que se dignó S. M. ... mandar se estimasen [los ejercicios literarios ejecutados en ellas] con los ejecutados en la Universidad para las pretensiones y ascensos de los Profesores de la Academia» ${ }^{18}$.

Pues bien, un hecho grave era denunciado, en 1768, por don Manuel de Aganza en nombre de las academias de San José y de Santa María de Regla. Aganza exponía al Consejo que:

«el Secretario de la Universidad inserta los Ejercicios de la Academia en las certificaciones que despacha a los interesados; pero cuando esta misma inserción debiera practicarse comprendiendo los méritos de la Academia en los informes que se hacen y remiten por la Universidad para las Cátedras de Leyes y Cánones, experimenta el notabilísimo perjuicio de que no se practica así, y acaso esta omisión no es sin estudio particular, porque comprendiéndose en los informes los ejercicios privados que en su Colegio independiente del cuerpo de Universidad hacen los Colegiales de San Ildefonso, y no comprendiéndose los muchos y muy dilatados que los Académicos hacen en sus Academias, aunque públicos, necesariamente han de parecer más completas las certificaciones de títulos de los Colegiales, de que resulta ser éstos preferidos en las Cátedras a los Manteístas más antiguos y de más mérito de Universidad» ${ }^{19}$.

Así pues, las academias recibían su principal impulsión desde sectores manteístas, que con ellas pretendían acrecentar méritos. Los colegiales, primero con métodos sórdidos como los denunciados por Manuel de Aganza y luego de manera institucional, tratarán de controlar unas iniciativas que se desarrollan, en gran parte, fuera de la Alma Mater. El Plan de Estudios de Alcalá integra las dos academias de San José y de Santa María de Regla ${ }^{20}$,

des», e inspiraron los planes de estudios de 1807 y 1824 . Vd. M. Peset, La enseñanza del derecho y la legislación sobre Universidades durante el reinado de Fernando VII (1808-1833), in Anuario de Historia del Derecho Español, XXXVIII, 1968, p. 232, 239 y 246.

16 Sobre el funcionamiento de estas academias, vd. M. Peset y J. L. Peset, El refor. mismo de Carlos III..., p. 27-28.

17 F. Pérez Bayer, op. cit., in F. Aguilar Piñal, Los comienzos de las crisis universitaria..., p. 231.

18 Colección de las Reales Ordenes y Providencias dadas por S. M. y su Supremo Consejo, en razón de la enseñanza y gobierno de la Universidad de Alcalá de Henares desde el año de 1760. Con Apéndice de Reales Ordenes atrasadas, Alcalá de Henares, 1773, p. 20-21.

19 Ibidem, p. 21. Por una Real Provisión de 19 de julio de 1768 se dispuso la inclusión en los Informes de Cátedras de los ejercicios realizados en ambas academias.

20 «Podrá, pues, mandar el Consejo que se formalice la Academia de Cánones y la de Leyes en aquella Universidad... Respecto de que en Alcalá hay dos Academias de esta clase, se podrán conservar, formalizar y arreglar, por ser las palestras en que los cursantes adquieren 
pero, además pretende suprimir «todo paso o repaso público fuera de la Universidad». Se propone, por ejemplo, la constitución de una academia dominical de Teología, pero sugiriendo que «se deberán quitar y extinguir todas las Academias particulares, que con este nombre y el de Conferencias y Repasos se tienen fuera de la Universidad». Se contempla, sin embargo, una excepción significativa: «las Academias domésticas que para su privado ejercicio tienen los Colegios Seculares y Regulares de aquella Universidad de Alcalá» ${ }^{21}$.

Aunque el Poder aceptó la integración de las Academias de Alcalá, no cedió a la presión de los colegiales en su pretensión de mantenerse fuera del régimen común. La Resolución del Consejo por la que se aprobaba el Plan de Alcalá ordenaba al Rector lo siguiente:

\begin{abstract}
«que dentro de tercero día recojais de los Presidentes de las Academias particulares los libros y papeles concernientes a ellas, y dentro de otros ocho las formalizareis y establecereis en las Aulas de esa Universidad ...y hareis notificar a los Rectores y Prelados de los Colegios y Conventos donde existen ahora dichas Academias, que recojan las llaves de las Aulas donde se tienen y no permitan en adelante estas funciones en sus Casasn ${ }^{22}$.
\end{abstract}

Sin apuntar a privilegios colegiales, no habían faltado voces ilustres para defender las academias extrauniversitarias. En su Idea del nuevo método que se puede practicar en la enseñanza de las Universidades de España (1767), Gregorio Mayáns defendía el mantenimiento de las academias establecidas fuera de la Universidad, en razón de su utilidad, aunque no les dejara mucha autonomía:

«convendrá que se permita que fuera de la Universidad haya academias, en las cuales se repase o se dé aquello mismo que en la Universidad se enseña y por los mismos libros» ${ }^{23}$.

El punto de vista de Mayáns se explica fácilmente. En 1724, al ser nombrado catedrático de la Universidad de Valencia, había fundado en su casa una academia de repaso, «especie de clase privada o repetitorio» según M. Peset, en la que enseñaba a sus estudiantes los Comentarios de Vinio a

el manejo del derecho y la facilidad de defender, argüir y explicar en público" (vd. Real Provisión del Consejo que comprende el Plan de Estudios que ha de observar la Universidad de Alcalá de Henares, Madrid, 1772, p. 220-222). El subrayado es nuestro.

21 Ibidem, p. 209 y 221.

22 Ibidem, p. 242. La Resolución lleva fecha de 11 de diciembre de 1772.

23 M. Peset y J. L. Peset, Gregorio Mayáns y la reforma universitaria. Idea del nuevo método que se puede practicar en la enseñanza de las Universidades de España, Valencia, 1975, p. 303. 
las Instituciones de Justiniano ${ }^{24}$. Si en algunos casos puede pensarse en apetencias crematísticas de los profesores, no cabe duda de que, en otros muchos, eran las carencias de la enseñanza universitaria las que justificaban el desarrollo de estos circuitos paralelos de formación, con frecuencia nacidos de una o varias iniciativas particulares. En el ámbito de la formación jurídica las nuevas preocupaciones y el continuo aflujo de pretendientes letrados a Madrid explican el desarrollo de las pasantías y de las academias "prácticas» ${ }^{25}$. Deseo en los manteístas de aumentar sus posibilidades de colocación, carencias de la enseñanza oficial, iniciativas particulares, preocupación práctica... son otras tantas características de la planta con que se presentan unas academias que son, ante todo, pedagógicas.

Algunas iniciativas particulares se colocaron resueltamente, sin embargo, fuera de la influencia o de la integración universitaria. De suerte que si, en el interior de la Universidad, los antiguos concursos o repetitorios se convirtieron en las academias «formalizadas» y organizadas por los Planes de Estudios, y si otras juntas o círculos privados (que no siempre tomaron la denominación de academias) fueron recuperadas e integradas por las Universidades, también hubo juntas que, nacidas fuera de la Alma Mater, quisieron y consiguieron individualizarse y diferenciarse. De esta realidad da testimonio el Diccionario de Autoridades cuando define las «academias» como unas «juntas donde concurren los profesores de estas facultades para conferir y adelantar lo que conduce a su mayor perfección y aumento». Conviene, pues, no confundir aquellas juntas con esta otra «Junta o Congreso de personas eruditas, que se dedican al estudio de las buenas letras y a tratar y conferir lo que conduce a su mayor ilustración», de la que habla, igualmente, el Diccionario. Es este último supuesto se trata de las «Academias de Italia, España, Francia, y Portugal, llamadas Española, Francesa,

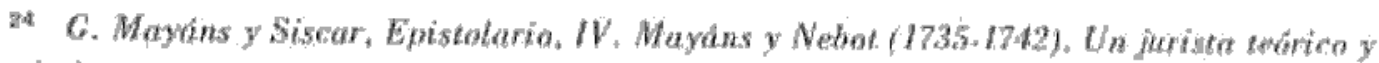
un praction, ranscripeión, notas y estudio preliminar de M. Peset, Vateneia. 1975. Én su estudio M. Peset señalis (j. LXXIIl) que acstáa academias perdidas por el rector y claustro. erun complementer usual de la enseñana en la cutodraw, y que matuales en la Universidud de Valencia, no eran aceptadas on Salamanca, pues se tenian por desolore para los alue las dabuns.

25 Cuandis, en 1768, don Manuel de Aganza, en nombre de las Acodemias de San José y de Santa Maria de Regla, dirige al Congejo la solichud antes referida, no deja de oluservar que las atcademias tenian wel cuidado de proveer de Pasantef a tudas los jovenes individuos que principian as astudio de las Leyes o del Derechn Canónico, por cuyo medio logran el adelantamiento que de atra forma no pudieran con la asistencia a las Caledras, porque las más suelen estar ahandonatas de los Catedraticoso (Colecéón de las Reales Ordenes... p. 20). 
Portuguesa y de la Crusca, que es la Italiana, instituidas principalmente para la formación de los Diccionarios de las lenguas". Con este modelo se identifican Academias como la de la Historia, la de Bellas Artes, y el proyecto de Academia Universal contemplado por Gil Novales ${ }^{26}$.

Fuera de la institución universitaria e, inicialmente, también fuera del ámbito del Poder, sin excesivas pretensiones eruditas, ciertas agrupaciones de letrados se formaron en Madrid, primero como juntas, más tarde como academias, en el sentido más arriba registrado. Estas corporaciones vieron comprometida su existencia en 1804, cuando, a instigación del Gobernador del Consejo de Castilla, Carlos IV decidió «resolver y mandar que no se admitan más individuos en las seis Academias de Derecho y Práctica de esta Corte; y que, por consiguiente, queden extinguidas cuando no haya número suficiente para que subsistan» 27 .

¿Cuáles eran las seis Academias a que se refería esta Real Orden?

La más antigua de ellas es la que, con la denominación de Junta Práctica de Leyes, se reunía, desde 1730, en el estudio del abogado Juan Antonio Torremocha. De ella formaría parte, en sus primeros y oscuros años madrileños, el golilla José Moñino, quien la llegaría a presidir y a cuya posterior influencia no es ajena la transformación de la Junta en Real Academia con el título de Santa Bárbara (Real Cédula de 20 de febrero de 1763). La sanción oficial venía así a reconocer la «utilidad» de la instrucción práctica dispensada en la Academia y del estudio del derecho patrio y del derecho público, en que fuera pionera esta Academia ${ }^{28}$. Años más tarde (1775) la instalación de la Academia en los Reales Estudios consagraba una labor que se había adelantado a las nuevas orientaciones pedagógicas y político-sociales (Planes de estudios, reforma de los Colegios Mayores...).

Hacia 1742, don Tomás de Azpuru ${ }^{29}$ convocaba regularmente en su casa a los miembros de otra Junta de Jurisprudencia Práctica. Debían ser

26 A. Gil Novales, op. cit., p. 10 y ss.

27 Real Orden de 26 de agosto de 1804 (Novísima Recopilación, ley IV, tít. XX, lib. VIII, n. 13).

28 A mayor abundamiento, remito a mi trabajo La Real Academia de Santa Bárbara de Madrid (1730-1808). Naissance et formation d'une élite dans l'Espagne du XVIII siècle, 2 vol., Toulouse, 1979.

29 El abogado Tomás de Azpuru fue primero Auditor en el Tribunal de la Rota, y, más tarde, representante de Carlos III en Roma, en donde falleció en 1772. Dos años antes había sido nombrado Arzobispo de Valencia, lo que prueba que don Tomás supo sacarle provecho a su estadía romana. 
éstos «sujetos de buena vida y costumbres, y que tengan suficiente capacidad ${ }^{30}$, virtudes que, ciertamente, concurrían en don Pedro Rodríguez Campomanes, miembro ilustre y director vitalicio de esta Junta, a la que una Real Carta de 23 de junio de 1773 concedió la facultad de poderse denominar Academia de la Purísima Concepción y estar aprobada con Autoridad Real ${ }^{31}$. Claro que, entre los miembros del Consejo que, conjuntamente con el conde de Aranda, firmaban la Real Carta, figuraba otro miembro distinguido de la Academia, don Juan Acedo Rico. Y cuando, también ya instalada en los Reales Estudios, la Academia acude otra vez al Consejo para solicitar la aprobación de nuevos estatutos, entre los miembros del Consejo que firman la autorización real figura don Pablo Ferrándiz Bendicho, quién, con anterioridad, había sido Presidente de esta Acade$\mathrm{mia}^{32}$. En los años difíciles del final de la centuria, la Academia proclamaba la libertad intelectual de sus miembros, pues, «conviniendo a todo jurisconsulto el conocimiento de los principios naturales en que se fundan las Leyes, e, igualmente, el de la historia de la Jurisprudencia y costumbres particulares de los pueblos» ${ }^{33}$, les invitaba a tratar y a profundizar «qualesquiera puntos que sean respectivos a estas materias», materias que el Poder consideraba entonces altamente subversivas.

Capitaneados por el abogado de los Reales Consejos don Antonio Sánchez Santiago cierto número de individuos de la Junta de Jurisprudencia Práctica se separaron de ella en 1771, formando una Academia de Jurisprudencia Teórico-Práctica y Derecho Real Pragmático, la cual encontró asimismo acomodo en los Reales Estudios de San Isidro en 1792. Aunque sus estatutos se aprobaron sin dificultad por el Consejo en $1775^{34}$, y aunque

30 Constituciones que se han de observar en la Junta de Jurisprudencia Práctica que se celebra en el Colegio Imperial de la Compañía de Jesús de esta Corte, [Madrid, 1764], p. 5. Adviértase el sistema de valores a que se hace referencia: el mérito, la capacidad...

${ }_{1}$ Constituciones de la Real Academia de Jurisprudencia Práctica de la Purisima Concepción..., Madrid, 1774, p. LII.

32 Constituciones de la Real Academia de Jurisprudencia Práctica establecida en los Reales Estudios de San Isidro de esta Corte, bajo la advocación de la Purísima Concepción, Madrid, 1784, p. XVIII.

33 Constituciones de la Real Academia de Jurisprudencia Práctica establecida en los - Reales Estudios de San Isidro de esta Corte, bajo la advocación de la Purísima Concepción, Madrid, 1796, p. XXII-XXIII.

34 A. H. N., Consejos, Leg. 623-7. Hay en este expediente un informe favorable del Colegio de Abogados, que encabeza como Decano don Francisco Sánchez Diego, Asesor General del Juzgado de Correos, quien, por entonces, presidía la Academia de Jurisprudencia Práctica y era, por lo que se ve, persona poco rencorosa. 
tuvo como Directores a los miembros del Consejo don Blas de Hinojosa y don Mariano Colón de Larreategui, Duque de Veragua, y al Inquisidor General Abad y Lasierra, no consiguió el preciado título de Real Academia, al parecer por el informe adverso de la Academia de Santa Bárbara, que pretendía ser la única academia de letrados habilitada a exhibir con fundamento tal prerrogativa.

Pretensiones más modestas tuvo en sus orígenes la Academia de Derecho Civil y Canónico de la Purísima Concepción. En 1762 algunos estudiantes de la Universidad de Alcalá que, concluido el curso, permanecían en Madrid, deseando perfeccionarse en las materias estudiadas en la Universidad, formaron una Junta para tratar cuestiones de uno y otro derecho. Estimulados con este ejemplo, al parecer, otros cursantes de la Universidad de Valladolid fundaron, en 1764, otra Junta en todo semejante a la primera. En 1766 ambas Juntas fusionaron originando la referida Academia de Derecho Civil y Canónico, en la que indistintamente se admitían ya cursantes de Alcalá, de Valladolid y de las demás Universidades mayores y menores ${ }^{35}$, y en 1780 el Consejo aprobó sus estatutos, reconociéndola así oficialmente y colocándola, según la frase consagrada, «bajo su inmediata protección». Tuvo también esta Academia por Protector a Campomanes ${ }^{36}$.

Un antiguo miembro de la Academia de Santa Bárbara, don Miguel Gabaldón López fundó, en su estudio, en 1769, una Academia Práctica de Leyes de estos Reinos y de Derecho Público con la advocación de Nuestra Señora del Carmen. Siendo Vicepresidente don Juan Pérez Villamil, esta Academia acudió al Consejo para que se aprobaran sus estatutos. El habitual informe del Colegio de Abogados señalaba la conveniencia de incrementar los ejercicios de derecho público, medida sin duda inspirada por el mismo Gabaldón que era, por entonces, Decano del Colegio y Presidente de la Academia ${ }^{37}$. El Consejo aprobó sus estatutos en 1779, una vez que la Academia nombró Protector vitalicio a su favorecedor don Santiago Espinosa, Fiscal del mismo Consejo.

De la Academia de Derecho de Carlos III sabemos que desde 1762 celebraba sus reuniones en el estudio de don Juan de Castanedo Ceballos,

35 Archivo de la Real Academia de Jurisprudencia y Legislación, Libro n. ${ }^{\circ} 1$. Primera formación de la Academia de la Concepción en 6 de abril de 1766, fol. 1.

${ }^{36}$ Lista o catálogo de los individuos actuales y jubilados que en este año de 1788 componen la Real Academia de Derecho Civil y Canónico..., Madrid, 1788, p. 5.

37 A. H. N., Consejos, Leg. 714-22. 
quién, con anterioridad, habia desempeñado cargos directivos en la Junta de Jurisprudencía. Präctica de la Purisima Concepción. De ésta se separaría también probablemente Castanedo para fundar su propia Academia, la cual, al acudir al Consejo, en 1784, solicitando la aprobación de sus estatutos, decia haber sido establecida por el mismo Tomás de Azpuru que creara la Junta de Jurisprudenoia Práctica ${ }^{38}$. Al fallecer Castanedo, Abogado del Ayuntamjento de Madrid y Consultor del Santo Oficio, en aquel mismo año de 1784, le sucedió en la Presidencia de la Academia don José Pérez Cáballero, del Consejo de Hacienda e Intendente interino del Real Jardín Botánico, a cuya impulsión se debe el que la Academia, al redactar de nuevo sus constituciones, se asignase como objeto «la instrucción práctica de los que se dediquen a la Abogacía, Judicatura, Gobierno y Policía de los Puebloss ${ }^{39}$. Esta oportuna y específica adecuación a los objetivos que los gobernantes habían fijado en la Real Orden de 9 de diciembre de 1783 en punto a las calidades de los pretendientes a los empleos de Corregidores y Alcaldes Mayores, explica el informe favorable de la Academia de Santa Bârbara y la ganción oficial rápidamente otorgada (Carta de 14 de mayo de 1785).

A estas academias cabría añadir la de Sagrados Cánones, Liturgia, Historia y Disciplina Ëclesiástica de San Isidoro. En 1757 doce presbileros, graduados en Cánones, que, ya empleados o en calidad de pretendientes, se encontraban en Madrid, decidieron consagrar sus ocios al estudio del Derecho Público-Canónicom Español (sic). Fsta manera de referirse a los tradicionales estudios canónicos denotaba ya la orientación regalista que animaba a los fundadores de esta Junta, inicialmente denominada de San Juan Nepomuceno, a la que, en 1763, se incorporó utra, también dedicada a las cíncias canónicas, que se reunía en el convento de San Martín. El crecido nủmero de asistentes, tanto ecleshástices como seglares, llevó a la Junta a redactar nuevos estatutos y a solicitar la aprobación oficial de sus tareas, lo que obtuvo en 1773. Desde entonces la Academia de Sagrados Cánones, Liturgia, Historia y Disciplina Eclesiástica de San Isidoro prosiguió, con renovadas fuerzas, el intento de formar de cada uno de sus Individuos un juicioso y verdadera Canonista español, que, noticioso de la Disciplina antigua y moderna de la lglesia, y, averiguadas, en cuanto sea posible, las causas de su variación y diversos ritos, por siglos, provincias y reinos,

\footnotetext{
38 A. H. N., Consejos, Leg. 923-30.

39 Constituciones de la Real Academia de Derecho con el título de Carlos III, Madrid,
} 1800 , p. 3. Estos estatutos datan de 1784. 
peculiar y principalmente en nuestra España, pueda, discerniendo lo falso de lo cierto y lo apócrifo de lo genuino, proceder con el debido conocimiento en las arduas materias que ofrece cada día la sociedad humana, siendo útil a su Patria» ${ }^{40}$. La trayectoria de la Academia se inscribe, pues, en la línea de reforma de los estudios teológicos y canónicos abierta por Macanaz en 1713 y que frenó, luego, la oposición de las Universidades (Alcalá y Salamanca, principalmente). Las corrientes regalistas, galicanas y jansenistas que inspiran esta trayectoria son las mismas que inspiraron la nueva ordenación de los estudios canónicos articulada en los Planes de Estudios. Queda por saber si esta orientación teórica tuvo una correspondencia efectiva en la práctica de las Universidades. La vitalidad y el atractivo que, por los mismos años, tuvo la Academia de San Isidoro, en tanto que circuito paralelo de formación y colocación, en abierta competencia con las Universidades, parece indicar que en éstas las transformaciones efectivas de la enseñanza fueron limitadas. Quizás convenga, pues, relativizar el juicio de quienes piensan que las ideas galicanas «recibieron su impulso fundamental con la introducción de estos planes de estudio, que formarán en esta ideología a los universitarios españoles a partir de este momento». El autor de este juicio ${ }^{41}$, prolongando el mismo y refiriéndose a las Cortes de Cádiz, estima que «en ellas los Villanueva, Llorente, Muñoz Torrero, etc., no harán sino exponer las ideas en que habían sido formados a su paso por las aulas universitarias» ${ }^{42}$. Un testimonio del propio Llorente viene a contradecir esta opinión. En carta fechada en Calahorra el 23 de abril de 1797 y dirigida a Manuel López Marichalar, por entonces Secretario de la Academia, decía Llorente estimar infinito su Academia (sic), porque «en ella fue donde yo logré los felices momentos de despreocuparme de muchas especies vulgares que había estudiado en la Universidad» ${ }^{43}$. La historia se escribía, pues, fuera de las aulas universitarias, en el discurrir de ciertas reuniones académicas. Por cierto, que la Academia de San Isidoro contó,

40 Constituciones de la Real Academia de Sagrados Cánones, Liturgia, Historia y Disciplina Eclesiástica, establecilla en esta Corte bajo la advocación de San Isidoro, Arzobispo de Sevilla, Madrid, 1773, p. IX.

41 A. Alvarez de Morales, La Ilustración y la reforma de la Universidad en la España del siglo XVIII, (2. a ed.), Madrid, 1979, p. 158-159.

42 Ibidem, p. 159.

43 Archivo de la Real Academia de Jurisprudencia y Legislación, Antiguas Academias, Leg. 30. Juan Antonio Llorente había ingresado en esta academia el 26 de noviembre de 1781 (Libro $10^{\circ}$ de Secretaría de la Academia de Ciencias Eclesiásticas de San Isidoro de Madrid, fol. 89). 
entre sus miembros honorarios al Inquisidor General Abad y Lasierra, a Jovellanos, a Martínez Marina, al mismo Villanueva...

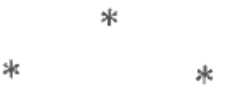

Las juntas (prácticas) de jurisprudencia, convertidas luego en academias, no fueron ni un amable salón o tertulia literaria, ni un «congreso de personas eruditas». Anacrónico sería proyectar sobre estos académicos la imagen de una academia concebida como reunión de sabios o especialistas indiscutidos de una ciencia o un saber. Ciertas academias del siglo XVIII se acomodaron, desde su nacimiento, a este modelo: academias de la Lengua, de la Historia, de Bellas Artes... Pero otras academias se diferencian claramente del mismo, como singularmente ocurre con las academias jurídicas. Estas juntas-academias no reunieron a personalidades confirmadas de la ciencia jurídica sino a jóvenes diplomados, que se ejercitaban, de esta guisa, en la práctica, primero, y, más tarde, en la crítica. Nacieron de un impulso privado, espontáneo, que respondía a unas catencias y a unas necesidades, y no fueron instituidas ex novo y de manera deliberada por las autoridades, sino reconocidas, realzadas, ...y aprovechadas. Su carácter y significación son por ello muy distintos de los que tuvieron otras academias o asambleas doctas del siglo de las Luces, asimilables a lo que eran en Europa las sociétés savantes.

«EI nombre de Academia lo puede significar todo», advertía, en 1789, un anónimo «magistrado», colaborador ocasional del Espíritu de los mejores diarios, y cuya preferencia iba a «aquellos cuerpos distinguidos por la sabiduría de todos sus miembros esicogidos» ${ }^{44}$. Pues bien, no todos los miembros de las academias madrileñas de letrados eran, forzosamente, muy sabios: si pidieron entrar en las academias fue, precisamente, para completar y mejorar una formación que les parecía inadecuada. De aquí el carácter más bien pedagógico que docto o sabio, que distingue las actividades de estas academias, y al que nunca renunciarán. Esta función pedagógica se asienta en la «práctica» y se inserta, por ello, en una línea de pensamiento de lejanos orígenes. Desde el siglo XIII se desarrolla una tendencia que empareja la invocación de cualquier texto jurídico con las opiniones de los juristas, más o menos célebres, que se habían pronunciado sobre el mismo. La opinión del intérprete llega así a prevalecer sobre la del juez, quien se

$44 \mathrm{Vd}$. Espíritu de los mejores diarios que se publican en Europa, 27 de abril de 1789, p. 1.133, n. 1 . 
inclina ante la autoridad del primero. Como los juristas legistas operan sobre los textos del derecho romano o del derecho canónico, y, escasamente, sobre el fondo jurídico nacional, llega a establecerse una distinción duradera entre la doctrina de los legistas (la «teoría»), que se sitúa, con frecuencia, al margen de los textos en vigor, cuando no los ignora, y la «práctica», que pretende abrir una interrogación sobre el derecho positivo. Así, desde el siglo XVI, se oponen una corriente teórica o doctrinal, de tintes más o menos escolásticos, y una corriente práctica, la cual se ocupa, inicialmente, de la res quotidiana, según la herencia del antiguo estilo judicial, es decir del funcionamiento concreto de oficinas y tribunales. En esta corriente, aún viva en el siglo XVIII, se insertan los golillas reunidos en academia, pero, en el transcurso del siglo, una evolución les lleva a subordinar la atención prestada a la res quotidiana a la interrogación sobre el viejo fondo jurídico nacional, a la investigación de las fuentes, a la crítica de los textos, al estudio de las instituciones. El vocablo «práctico» ha cambiado notablemente de sentido.

Aquella adhesión a la «práctica» y este cambio de sentido son, en sus orígenes, fruto de una reacción contra la enseñanza universitaria. Las academias de letrados del siglo XVIII se sitúan resueltamente fuera del ámbito de influencia de las Universidades. En éstas, según los términos de M. Peset, «por sus actuantes y factura, las Academias son un escalón pequeño en la enseñanza, extraordinariamente útil para que los cursantes vayan iniciándose en las ceremonias, actos y exámenes diversos de la compleja Universidad» ${ }^{45}$. Ahora bien, los letrados que frecuentan las academias madrileñas no buscan una preparación para afrontar «actos y exámenes» universitarios, sino para conocer las actividades y procedimientos de la Administración y de los Tribunales, es decir para afrontar la gestión de la res publica. A estos efectos la pedagogía tradicional no servía. Así, las juntas-academias pusieron en pie un arsenal pedagógico ad hoc, quizás no excesivamente original en su organización o en sus denominaciones, pero profundamente renovador en su funcionamiento y en sus resultados. La formación efectiva de los más jóvenes por los más «veteranos», el papel activo que los recién ingresados son invitados a desempeñar desde su admisión, la ausencia de un discurso magistral, la «autogestión» del conocimiento, son otros tantos elementos que renuevan singularmente los hábitos pedagógicos de la época y su monótona repetición universitaria. De modo que cuando en 1785 algunos ilustrados -Meléndez Valdés, Ramón de

45 M. Peset y J. L. Peset, El reformismo de Carlos $I I I \ldots$, p. 28. 
Salas, el Dr. Ayuso, el Dr. Ocampo...- quieren crear, en la Universidad de Salamanca, una Academia de Derecho Español y Práctica Forense, el modelo inspirador se asemeja notablemente a las academias prácticas creadas en Madrid, fuera de la Universidad, y tiene ya muy poco que ver con las academias universitarias del tipo de las organizadas por los Planes de Estudios ${ }^{46}$. Aunque, desde un punto de vista institucional, no se trataba de algo totalmente nuevo (otras academias funcionaban en la Universidad de Salamanca), desde la perspectiva abierta por las motivaciones de los inspiradores del proyecto nos encontramos con unos lineamientos familiares. Se trata de presentar una alternativa a la pedagogía tradicional y escolástica imperante en la Universidad de Salamanca, muy refractaria, como es sabido, a las reformas promovidas en tiempos de Carlos III. La alternativa consiste en orientar la formación de los futuros letrados hacia las realidades profesionales y sociales, gracias a una pedagogía atenta a los aspectos prácticos y experimentales, liberada del férreo corsé que imponían las envejecidas estructuras universitarias ${ }^{47}$. Las resistencias que encontró el proyecto provocaron la cólera de Meléndez Valdés ${ }^{48}$. No resulta difícil, desde luego, emparejar los reproches formulados por el sector tradiciona-

46 Sobre este asunto, vd. G. Demerson, Don Juan Meléndez Valdés et son temps (I7541817), París, 1962, p. 115-116; D. Mateo del Peral, Sobre Ramón de Salas y la incorporación de la "Economía Civil» a la enseñanza universitaria, in Investigaciones Económicas, 6, 1978, p. 179-180; y S. Rodríguez Domínguez, Renacimiento universitario salmantino a finales del siglo XVIII. Ideología liberal del Dr. Ramón de Salas y Cortés, Salamanca, 1979, p. 124-128.

47 «El uso de la lengua popular frente al latín sería obligatorio en las disertaciones que se celebrarían una vez por semana, los jueves entre nueve y doce de la mañana, a lo largo del invierno, y una hora antes durante el verano, mientras persistiera el curso ordinario. La apertura del curso había de consistir, preceptivamente, en una uoración castellana» en que su profesor abordaría el estudio de «las partes» que en la «legislación precisasen reforma». Y el Director debería reunir las condiciones propias de un sujeto de talento, aplicación, y gusto, capaz de señalar a sus discípulos lo que necesita[se]n estudiar y aprender para hacerse buenos letrados, manifestándoles los libros donde los ha[bía]n de buscar, ...y de notar los defectos de sus escritos y oraciones, y enmendarlos» (D. Mateo del Peral, op. cit., loc. cit.). No otra cosa preveían, con apreciable anterioridad, las academias de letrados extrauniversitarias.

48 Meléndez Valdés «indigné par les objections ridicules que l'on avait faites au projet... dénonça la stupidité de certains avis proférés, par exemple que l'Université n'avait pas à former d'hommes politiques; que le retard de l'agriculture et des manufactures espagnoles, les rapports commerciaux avec les Indes ou les modifications de la législation réclamées par les circonstances étaient des questions trop ardues pour être débattues dans cette Académie» (G. Demerson, op. cit., p. 116). Evidencia del peso de las viejas mentalidades en la Universidad de Salamanca: la academia no consiguió reunirse, y, en 1797, todavía había profesores en el Claustro de Salamanca que opinaban que «la institución de una Academia de Práctica ni es útil ni consiguiente a las intenciones de la Universidad» (S. Rodríguez Domínguez, op. cit., p. 128). 
lista de Salamanca y recogidos por Batilo con las preocupaciones dominantes en las academias jurídicas de Madrid, empeñadas en formar «hombres políticos», tanto en el sentido amplio como en el sentido estricto de la palabra.

La prueba de ello la encontramos en la importancia conferida por las academias a la institución del corregimiento. Las academias jurídicas fueron al tiempo juez y parte en la formación del nuevo tipo de corregidor dibujado por el poder ilustrado, en la medida en que se les atribuyó la facultad de «examinar» las disertaciones que debían presentar, ante el Consejo, los candidatos a corregimientos y alcaldías mayores, siendo así que muchos de los mismos habían pasado, antes, por las academias. No deja de ser, ciertamente, relevante este papel conferido a las academias en el marco del programa ilustrado, si reparamos en que el corregimiento es una pieza maestra en la reorganización de la administración periférica del Estado, indispensable dentro del esfuerzo de centralización administrativa emprendido por los Borbones.

El nuevo corregidor es el prototipo del magistrado ilustrado y patriota, deseado por el poder reformista y con frecuencia invocado por los letradosacadémicos en sus discursos. Es que las academias jurídicas querían desempeñar un papel capital -papel que el Poder, complaciente y cómplice, contribuía a asentar- en el proceso arriba señalado. De suerte que, en su conjunto, estas academias configuran un embrión de escuela, confuso anticipo de una escuela nacional de administración, que aspira a formar un cuerpo, una élite eficaz y competente de letrados y de funcionarios -una tecnocracia se diría hoy-, fieles y comprometidos con las reformas emprendidas o proyectadas por los gobernantes. Contrariamente a lo que cabía esperar, este modelo embrionario no cuaja en el siglo XIX. El espíritu elitista -élite de conocimientos y no de nacimiento- que habían desarrollado estas academias se extingue con ellas. Cuando, hacia 1830 , renace la vida corporativa de las academias jurídicas, y cuando, en 1840 , fusionan originando la Academia Matritense de Jurisprudencia y Legislación, la nueva institución se asimila ya a una société savante y no a aquella gran escuela nacional de las Luces - al menos de las Luces jurídicas y administrativasque habían dibujado las academias madrileñas en la centuria anterior. Con ello el liberalismo español había perdido una de sus posibilidades, la de consolidar la emergencia de un poder administrativo, sólido y relativamente autónomo, generador al tiempo que beneficiario de una constitución administrativa, que habría podido contribuir a asegurar progresivamente el cambio de sociedad, más allá de los cambios de constitución política y aún de 
política. Las fluctuaciones del siglo XIX español en vez de ser así atenuadas, fueron agravadas en sus consecuencias, por los frecuentes cambios de personal administrativo, en los que el caciquismo y las clientelas venían a sustituir al elitismo reivindicado por los Mora y Jaraba ${ }^{49}$ y otros golillas formados en la escuela práctica de pensamiento que las academias de letrados habían impulsado. Las fuentes ideológicas de aquél elitismo son las inherentes al tema de la «felicidad general» como finalidad primera del Estado, que subyace en las doctrinas de los «naturalistas» (impulsores del derecho natural), de los cameralistas y de los fisiócratas; a través de la idea de que el Estado, para asegurar la pública «felicidad» necesita una administración renovada, asentada en las competencias y en el mérito, y en la que el papel del agente individual se desarrolla en detrimento del viejo sistema de consejos ${ }^{50}$; a través de la atención concedida a la educación, que procura

49 Frente a quienes, como el anónimo autor de un Discurso político sobre el estado presente de la Monarquía (1661), criticaban «el demasiado punto y estimación a que se ha subido la toga» (B. N. M., Ms. 13513), el jurista don Pablo de Mora y Jaraba propugnaba la expansión de las funciones de los letrados, cuestionando la competencia de los denominados ministros de capa y espada, en un escrito, hasta ahora inédito, titulado La ciencia vindicada ( $\mathrm{J}$. Sempere y Guarinos, Ensayo de una biblioteca de tos mejores escritores del reinado de Carlos III, Madrid, 1785-89, t. IV, p. 120, había ya mencionado, al hacer el inventario de los escritos de Mora y Jaraba, La ciencia vindicada, o impugnación del error en que están algunos de que los literatos no son hábiles para los empleos de gobierno. Una copia, con el título La ciencia vindicada, escrita por don Pablo Mora Jaraba siendo abogado, en favor de los de su profesión, y contra los plumistas, llamados comúnmente corbatas, existe en la B. N. M., Ms. 11038). La obra más conocida de Mora y Jaraba es su Tratado crítico. Los errores del derecho civil y abusos de los jurisperitos (Madrid, 1748), en el que denunciaba el divorcio existente entre la enseñanza universitaria, basada en los derechos romano y canónico, y la práctica judicial, asentada en el derecho patrio. A. propósito del proyecto, esbozado por Mora y Jaraba en su Tratado crítico, de creación de un código hispano-romano, vd. M. Peset, Una propuesta de código romano-hispano inspirada en Ludovico Antonio Muratori, in Estudios en homenaje al profesor Santa Cruz Teijeiro, II, Valencia, 1974, pp. 239 y ss. Sobre los antecedentes del tema de la situación social y aspiraciones políticas de los letrados es fundamental el reciente libro de J. M. Pelorson, Les Letrados, juristes castillans sous Philippe III. Recherches sur leur place dans la société, la culture et l'Etat, Le Puy-en-Velay, 1980, in totum.

50 El corregidor «ilustrado y patriota» es el prototipo de este agente, convertido en «el gran instrumento de burocratización del Estado", por decirlo con palabras de E. García de Enterría, Revolución francesa y administración contemporánea, Madrid, 1972, p. 82. En lo alto de la pirámide administrativa la creación de los Secretarios y, en 1787, la de la Junta Suprema de Fisado, obra de Finridabianca, respondía a la misma dinámien. Lus Secretarios de Estado y Al Despocho tratan directamente con el Rey, invadon las oumpelencias de los Consejos, y deciden wpor da via reservadus, es decir ignorando, con freatuenia, a estos mismos Consejos. Vd. J. A. Eacudero, Las Sertefarios de Estado y del Despacho, Madrid, 1969; y Los cambios ministeriales a fines del Antiguo Régimen, Sevilla, 1975. 
la normalización de las conciencias, y a la formación técnica de las élites encargadas de concretar la aspiración a la felicidad del común.

No es de extrañar, por todo ello, que en el impulso inicial -el que diera la Junta-Academia de Santa Bárbara, secundada, luego, por las demás academias jurídicas madrileñas- pesara fuertemente el modelo original y teórico del Colegio Mayor, modelo admirado y detestado al mismo tiempo, pero en todo caso muy presente en la mente de aquellos golillas. Podría, incluso, decirse que, frente a la degradación y a la decadencia del Colegio Mayor, aquellos letrados ilustrados, ( 0 , al menos, inquietos), de origen manteísta en su mayor parte, quisieron recrear un nuevo tipo de Colegio Mayor, sano y austero, riguroso y protector, adaptando algunos de sus elementos constitutivos a las Luces del siglo y a los fines que las juntasacademias se habían asignado. Atracción, pues, de un modelo hecho por y para las élites, aunque de élites ya anacrónicas se tratase, y modernización de un viejo principio. Atracción, pero también repugnancia: algunas incidencias de la vida académica ${ }^{51}$ traducen el rechazo por parte de aquellos letrados de ciertas imposiciones, que, situadas en el ya de por sí riguroso marco de las actividades académicas, eran tanto más insoportables cuanto que recordaban algunas de las costumbres universitarias y colegiales más anacrónicas. En una etapa posterior, al filo de 1770 , y sin abandonar totalmente el modelo originario, los letrados-académicos toman distancias con respecto al mismo (en los estatutos de la Academia de Santa Bárbara, por ejemplo el término «huéspedes», de connotación colegial, es sustituido por «jubilados»), y tratan de precisar la imagen de escuela de cuadros del Estado ilustrado y de buenos profesionales que quieren ofrecer ante el público y ante el Poder. La aplicación, por lo general decepcionante, que de los Planes de Estudios hicieron las Universidades, el fracaso de la reforma de los Colegios Mayores, no podían más que confortar la posición de las academias y eforzar el esquema en que éstas se asentaban. El desarrollo lógico de este esquema produciría las inquietudes que, en un poder receloso, explican la Real Orden de 26 de agosto de 1804. Es que por entonces las academias iban ya revistiendo ciertos aspectos propios de las denominadas por Augustín Cochin «sociétés de pensée» ${ }^{52}$. Y ello sin que los letrados

51 Cf. A. Risco, La Academia de Santa Bárbara..., cit., I, p. 138 y ss.; Flajos y reflujos del "Motín de Esquilache», in Cuadernos de Historia Moderna y Contemporánea, 3, 1982.

52 A Augustín Cochin corresponde el mérito de haber señalado el papel de las por él denominadas «sociélés de pensée» en las explosiones revolucionarias, y particularmente en la francesa. Estas sociedades (círculos, logias, academias, clubs patrióticos, culturales o económicos) abundan en la Europa de la segunda mitad del siglo XVIII, y, aunque obedezcan a 
académicos abandonaran la finalidad de obtener una buena formación técnica, puesta al servicio de un Estado, cuyos cimientos, de manera más o menos consciente, estaban zapando al terminar la centuria.

Así, conviene interpretar las repetidas (en unas y otras academias) invocaciones a la «decadencia» de estos cuerpos como la percepción que tienen los contemporáneos de la tensión entre una Academia-Escuela de cuadros y una Academia-«société de pensée». Esta tensión, según las circunstancias, se atenúa o se hace evidente, abriendo períodos de crisis, crisis que traducen, en el interior de las Academias, el peso del contexto exterior e internacional. Persiste aún la tendencia a identificar el reinado de Carlos IV con la "reacción» que el curso de la Revolución francesa provocó en España. Esta apreciación, algo simplista, debe ser matizada, pues parte de un equívoco. Ya advirtió Menéndez Pelayo -autor poco sospechoso de adhesión incondicional a las Luces- que era «un error histórico, bastante difundido por cierto, el creer que con el advenimiento de Carlos IV se paralizó el movimiento cultural del siglo XVIII». Con posterioridad Carlos Seco ha rehabilitado el denostado reinado de Carlos IV, aunque para ello haya gratificado quizás con exceso a Godoy. Parece que el error antaño denunciado por Menéndez y Pelayo provenga a menudo de una confusión entre crisis política y crisis intelectual de la Ilustración. La primera es evidente y plasma en disposisiones defensivas ante todo lo que llega de allende los Pirineos -ya se trate de escritos revolucionarios o contrarrevolucionarios, aspecto éste último de la cuestión poco estudiado en relación con el desarrollo del pensamiento reaccionario español-, en la agravación de los controles, en los cambios registrados entre el personal político y administrativo. En cuanto a la segunda, no debería ser asimilada, pura y simplemente, a la primera. No se trata, claro, de soslayar la incidencia de la crisis política sobre la producción intelectual, pero no cabe reducir ésta a los impresos o periódicos publicados a un lado u otro de los Pirineos. La atención excesiva, cuando no exclusiva, que se ha prestado a los impresos -e insisto en que no se trata de obviar las dificultades de circulación o de realización- ha conducido, frecuentemente, a apreciaciones sumarias. Un correctivo a esta visión lo proporciona el estudio de la censura, que nos descubre tanto las condiciones precisas de aplicación de las medidas represivas y de control, como buena parte de las producciones intelectuales que no llegaron a ver el

preocupaciones diversas, un mismo espíritu "patriótico» y «filosófico» las anima. Sobre la obra de Cochin, vd. el reciente juicio de F. Furet, Penser la Revolution Française, Paris, 1978, p.
212 y ss. 
día ${ }^{53}$. Otras fuentes de conocimiento, como las producciones de las academias aquí consideradas, al haber permanecido más o menos secretas, contribuyen a asentar una evaluación más matizada del reinado de Carlos IV. Para las academias, en efecto, los últimos años del siglo XVIII figuran entre los más ricos y fructuosos desde el punto de vista de la producción intelectual. Si los estatutos en estos años revisados (las Academias de Jurisprudencia Práctica y de Derecho Civil y Canónico se dotan de nuevos estatutos en 1795, la de Santa Bárbara en 1798) respetan el aspecto pedagógico, el aspecto de escuela, que, desde sus orígenes, tenían las academias, no, por ello, dejan de invitar a sus miembros a la libre discusión. Ya aludí a la manera en que la Academia de Jurisprudencia Práctica animaba a sus individuos a profundizar «cualquier punto» en materias que el Poder consideraba con suspicacia (supra); la Academia de Derecho Civil y Canónico distribuía el temario de sus disertaciones de modo que «todos encuentren materias análogas a sus ideas y a su gusto" ${ }^{54}$; en la Academia de Santa Bárbara la «verdad» se construye a través de la discusión y del voto ${ }^{55}$. Todo ello evoca irresistiblemente algunos de los caracteres de las denominadas «sociétés de pensée».

Nada más lógico, en realidad, si consideramos que la crisis política de

53 Remito a las investigaciones de L. Domergue, La censure des livres en Espagne à la fin de l'Ancien Régime, (Thèse de Doctorat d'Etat, Université de Toulouse-Le Mirail, 1976).

54 Constituciones de la Real Academia de Derecho Civil, Canónico y Patrio, con el título de la Purísima Concepción, (1795), Constitución IX.

55 El académico disertante comenzaba exponiendo el tema sobre el que se proponía disertar y su opinión personal en el supuesto de que la cuestión fuese «dudosa», es decir sujeta a discusión. Luego intervenía el individuo de más reciente ingreso, quien debía preparar un «apuntamiento» de «todas las noticias que haya podido adquirir sobre aquella materia, las ideas y reflexiones que se le ocurran y los libros que mejor traten de ella». Los demás académicos eran, a su vez, invitados a completar este trabajo. El Presidente -0 su sustitutorealizaba, luego, una síntesis de todo lo expuesto, añadiendo su propia opinión. Con todo ello el disertante reelaboraba su discurso, el cual pasaba entonces a manos de los censores de la Academia. La víspera de la lectura el autor del texto presentaba dos o tres uconclusiones» en las que resumía «toda la substancia» de su trabajo. Si la Academia aprobaba las "conclusiones», el Presidente encargaba a tres académicos la presentación de «argumentos», en que se suscitaban objeciones al disertante. Intervenían luego, el día de la lectura y con las observaciones pertinentes, los demás académicos que lo deseasen. Si el autor del discurso no pudiese resolver alguna de las cuestiones planteadas, al Presidente correspondía hacerlo «con el artificio y disimulo que exige la urbanidad» $y \sin$ ofender «el amor propio» del autor. A continuación éste salía de la sala y la Academia, por medio de un voto, decidía si el trabajo merecía ser examinado (con vistas a una eventual publicación) o simplemente archivado, si no era digno de tal honor (Constituciones de la Real Academia de Derecho Español, 1798, Sección 2. ${ }^{\text {, }}$ Artículo 1; y A. Risco, La Real Academia de Santa Bárbara..., cit., I, p. 311-313). 
las Luces españolas no interrumpió el discurrir de las ideas y que, además, estas mismas ideas no encontraban en la impresión su único medio de difusión, sino también -y quizás en más amplia medida- en la circulación subterránea de manuscritos y traducciones (patentadas o no), en las discusiones que se desarrollaban en los salones, las sociedades, las academias..., sin olvidar las conversaciones privadas o de grupo ${ }^{56}$, que los acontecimientos de Francia y «el estado de la Monarquía» suscitaban. De modo que la crisis intelectual de la Ilustración no es sino la crisis de conciencia de los ilustrados, antaño reunidos alrededor del proyecto común de levantar una «Nación», todavía mal soldada, y de procurarle la «felicidad», y luego desorientados al ver la quiebra del esquema que sustentaba este proyecto y la desagregación que implicaba la disociación de intereses individuales o de grupo, es decir la ruptura de aquella unanimidad. Así se entienden los esfuerzos desplegados en las academias de letrados para preservar una cohesión que se adivina frágil, amenazada por el cruce de las corrientes que agitan a los círculos ilustrados, y un espíritu de grupo socio-profesional, patrimonio precioso de unas academias formadoras de una élite de ancien Régime, que la eclosión de intereses y percepciones divergentes, anunciadora de un régimen nuevo, comprometía gravemente. Así se aclaran también ciertas defensas enardecidas, y, a veces, mal interpretadas, del despotismo (adjetívese de ilustrado o de ministerial), al que se adherían, entre 1760 y 1790, los letrados académicos, porque, proporcionándolos colocación, contribuía a su «felicidad» tanto como a la de la «Nación». Tan solo a medida que se va perfilando la ambigüedad del reformismo, a medida que las tensiones propician definiciones y compromisos, los académicos tenderán a ampliar e incluso a modificar su proyecto. Con lo cual iban preparando aquellos embriones de «sociétés de pensées que tanto inquietaron al Poder entre 1804 y 1807. El 15 de junio de 1807, en efecto, el Consejo se dirigfa al Gobernador de la Sala de Alcaldes en solicitud de un informe sobre la ejecución de la Real Orden de 1804 (supra), y siete meses más tarde, día por día, le instaba a que diera cabal cumplimiento a la mencionada disposición ${ }^{57}$.

Para entonces, sin embargo, las academias de letrados habían cum-

56 Sobre este cireuito, tan poco explorado, pueden rastrearse datos en los procesos inquisitoriales. Precisamenle en uno de ellos -el de don Jerinimo Portatui y Covarrubias, oficial de la Contaduria Mayor de Méjico, denunciado a la Lnquisición en 1785-, que espero publicar en breve, he enconirado interesantes nuticias al respecto.

57 A. H. N., Consejos, Sala de Alcaldes. Libro de gobierno. 1807, fol. 460 y ss. A mayor abundamiento vd. A. Risco, La Real Academia de Santa Bárbara..., cit. I, p. 213-223. 
plido su parte de contrato, contribuyendo a la formación de una élite, cuyas ramificaciones se extendían por todo el Reino y también por tierras americanas. Un criterio, en exceso restrictivo, pendiente sobre todo de las lecturas, inclinaciones o preferencias literarias de los ilustrados -aunque, en ocasiones, no quede del todo claro si se trata de las de los ilustrados o de las de los utilizadores de aquél criterio-, ha venido reduciendo el ámbito de la Ilustración española a los «sujetos excelentes» de que hablaba de Laborde o a la «minoría selecta», cara a Sarrailh. Esta apreciación quizás deba ser ya hoy revisada. Cierto, las Luces no fueron en España lo que hoy se llamaría un «movimiento de masas». En ningún país de Europa -una Europa todavía bien bárbara y, en terribles proporciones, analfabeta- lo fueron. Sin embargo, cabe pensar que las élites que construyeron el siglo XVIII español -si también cabe acuerdo sobre el significado del término- tienen ramificaciones más importantes y caracteres más diversificados que los que, antaño, se definieron. En su parte correlativa, y, pienso, que no desdeñable, los letrados-académicos suministran buena prueba de ello. Primero aplicaron su celo a la realización de aquella «revolución oficinesca, togada, doctoril y absolutista» que tanto irritaba a don Marcelino ${ }^{58}$. Con idéntico fervor prepararon luego, en persona o por la fuerza de las ideas que sus herederos de principios del XIX propagaron, el despertar, en Cádiz, de una nueva conciencia, que no se explicaría sin tener en cuenta el trabajo incesante de aquellas generaciones de (en su mayor parte) oscuros letrados, que, a lo largo de más de tres cuartos de siglo, fueron identificando su propia labor con la «felicidad» de la «Nación», en el seno de las Academias.

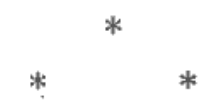

Habráse ya comprendido que las Academias de que se hace aquí cuestión no responden al modelo analizado por Gil Novales. Convergencias hay, claro está, aunque sólo fuese la de «reunir afanes a fin de crear un ambiente intelectual» ${ }^{59}$. Los orígenes (juntas particulares) fueron también del mismo tipo en una Academia como la de la Historia ${ }^{60}$. Y, desde luego, unas y otras academias aparecen relacionadas con el poder monárquico y los intentos de reforma ${ }^{61}$.

58 M. Menéndez Pelayo, Historia de los heterodoxos españoles, II, Madrid, 1956, p. 476.

59 A. Gil Novales, op. cit., p. 3.

60 Ibidem, p. 6.

61 Ibidem, p. 8. 
Quizás parezca, sin embargo, un tanto perentorio el afirmar que el Consejo de Castilla era «enemigo de todo cuerpo científico» ${ }^{62}$. Todos los dictámenes del Consejo relativos a las diferentes academias de letrados que he podido consultar, fueron favorables, sin excepción ${ }^{63}$. Y si, desde luego, no forzosamente la adopción de títulos más ambiciosos por parte de las academias indica "afán de ciencia en sus miembros»" ${ }^{64}$, es que las motivaciones no siempre eran simétricamente coincidentes. Para algunas academias, de la tipología estudiada por Gil Novales, lo fundamental sería la ciencia, la erudición. Son las academias que podríamos denominar eruditas, cuyo modelo ideal sería la non nata Academia Universal. Para otras, como las academias de letrados, lo fundamental es la instrucción, la renovación de una determinada formación y las miras, bajas o elevadas, subyacentes. Son éstas, ante todo, instituciones pedagógicas, en las que realmente la palabra Academia recobra todo su sentido pedagógico ${ }^{65}$, sí, pero un sentido pedagógico innovador y alejado de las prácticas y rutinas universitarias, y para las cuales la consecución del preciado título de Real Academia, es decir la dependencia directa del Monarca o del Consejo, era una manera de resguardarse frente a los ataques de otras instituciones celosas de su monopolio pedagógico.

Instituciones pedagógicas, pues, en donde se experimentaba una enseñanza renovada, que el Poder había hecho suya, pero que no conseguía imponer francamente en las instituciones oficiales de enseñanza. Pero es que, además, la renovación de la enseñanza del derecho que operan las academias de letrados, a través del triple eje derecho patrio (= antirromanismo), derecho público (= regalismo), y derecho natural (= racionalismo), desemboca en una ambición profesional, en un elitismo corporativista, y, en última instancia, en una mutación socio-política, que es la que intenta, precisamente, el despotismo ministerial de los ministros golillas. Así se explica *el interés de Floridablanea por el tema académicon ${ }^{66}$, en particular por las academias pedagógicas - no olvidemos el impulso decisivo que dió para la erección de la Academia de Santa Bárbara-, y prácticas to aplica das), tan alejadas de aquellas otras que Iriarte tratara, ante el mismo

62 Ibidem, p. 5.

63 A. H. N., Consejos, Leg. 623-7; 624-18; 714-22; 735-34; 826-37; 923-30.

64 A. Gil Novales, op. cit,, p. 17.

65 Como el mismo Gil Novales no deja de advertir, a propósito del proyecto de Academia de Ciencias de Jorge Juan, Luis Godin y José Carbonell, señalando «lo novedoso y grave» del intento (op, cit., p. 15).

66 Ibidem, p. 20. 
Floridablanca, de «academias de conversación» ${ }^{67}$. La Academia, decía Iriarte, se funda para trabajar. Y en la Academia se trabaja, pensaban los letrados académicos, para, luego, colocarse, poniendo las luces adquiridas al servicio de la patria. ¿Y qué mejor servicio que la penetración de los aparatos administrativos y el desplazamiento de quienes inocua o inicuamente los ocupaban?

Con el término "Academia» se encubren realidades muy distintas. Las concomitancias quedan relegadas a un segundo plano ante las sustantivas diferencias que existen entre aquellas «academias de conversación», denunciadas por Iriarte, las diversas academias eruditas, entregadas a un proyecto más o menos ideal y a largo plazo, y estas academias de letrados, academias formativas con objetivos muy concretos e inmediatos, y unas pretensiones o ambiciones de considerable trascendencia socio-política. Creo que la distinción no carece de relevancia, para que, llegado el caso, sepamos de que estamos hablando, si de precisar la noción de Academia en el siglo XVIII español se trata.

Antonio Risco

Université de Toulouse-Le Mirail

$67 \quad$ Ibidem, .p. 19. 